\title{
Effect of Pilates Exercises on Abdominal Muscle Strength in Post Menopausal Women
}

\author{
NAHLA M. SHAKER, M.Sc.*; SOHEIR MAHMOUD ELKOSERY, Ph.D.*; \\ HAZEM S. EL ASHMAWY, M.D.** and AFAF M. MAHMOUD BOTLA, Ph.D.* \\ The Departments of Physical Therapy for Woman's Health*, Faculty of Physical Therapy, Cairo University and \\ Obstetrics \& Genecology**, Faculty of Medicine, Cairo Universty
}

\begin{abstract}
Background: Menopause is the time that marks end of woman's menstrual cycle, occurring on average around 51 years of age. It associated with decline in estrogen level which lead to increase central obesity as well as decrease muscle strength and endurance. Pilate exercises belong to a group of so-called body mind exercises which improve mental and physical status, increasing muscle strength and flexibility.

Aim of Study: This study aimed to see the impact of Pilates exercise on abdominal muscle strength in post-menopausal women.
\end{abstract}

Subjects and Methods: Thirty post-menopausal women complaining from belly abdomen were selected randomly from out-patient clinic of faculty of physical therapy to participate in this, their age ranged from 50-60 years, their BMI not exceed $35 \mathrm{Kg} / \mathrm{m}^{2}$, all of them had number of parities ranged from 2-4 times, their menstrual cycle had stopped at least one year ago. Subjects were subdivided randomly into two groups each with fifteen participants, group A practiced selected exercise program that include (static abdominal, pelvic rocking and postural correction exercises) for $20 \mathrm{~min} / \mathrm{session}$ twice per week for 12 weeks and group B performed the same program as for group A plus Pilates exercises for another $60 \mathrm{~min}$. Outcome to be studied in this research was abdominal muscle strength (peak torque, total work and average power) using Isokinetic dynamometer.

Results: There was a significant increase in peak torque, total work and average power in abdominal muscles in group $\mathrm{B}$ who perform Pilates exercise rather than group A ( $p>0.001)$

Conclusion: Pilates exercise is an effective modality to increase abdominal muscle strength in post-menopausal women

Key Words: Menopause - Pilates exercise - Isokinetic dynamometer.

\section{Introduction}

MENOPAUSE is a natural phase of life for women, marked by hormonal change and the cessation of menses, occurring on average at around 51 years

Correspondence to: Dr. Nahla M. Shaker, The Department of Physical Therapy for Woman's Health, Faculty of Physical Therapy, Cairo University of age [1]. The Stages of Reproductive Aging Workshop (STRAW) established that menopause could be defined by several key phases using the principal criteria of the menstrual cycle variability. These included late reproductive, menopause transition (early and late) and post menopause (early and late) stages. Based on hormone changes, the approximate length of the menopause transition is around 1-3 years [2].

The menopause transition is experienced by 1.5 million women each year and often involves troublesome symptoms, including vasomotor symptoms, vaginal dryness, decreased libido, insomnia, fatigue, and joint pain [3]

Menopause is associated with a decline in estrogen levels, which could lead to an increase in visceral adiposity as well as a decrease in bone density, muscle mass and muscle strength. This decline in muscle mass, known as sarcopenia, is frequently observed in postmenopausal women [4] Aging is associated with a progressive loss of bonemuscle mass and strength. When the decline in mass and strength reaches critical thresholds associated with adverse health outcomes, they are operationally considered geriatric conditions and named, respectively, osteoporosis and sarcopenia [5].

It is estimated that the prevalence of sarcopenia in postmenopausal women is $10-40 \%$ [6] and although it can result from other conditions, one of the principal causes is hypoestrogenism [7]

Weakness of the abdominal muscles lead to diminish the overall abdominal integrity and bulging of the abdominal wall, which can result in cosmetic defects, psychological discomfort (i.e. body image) [8], and it also can result in farther 
related complains such as back pain, lumbo-pelvic pain, and pelvic instability [9].

Pilates exercises belong to a group of so-called body-mind exercises, where the focus is on controlled movement, posture, and breathing. Pilates (pronounced: puh-lah-teez) improves mental and physical well-being, increases flexibility, and strengthens muscles through controlled movements done as mat exercises or with equipment to tone and strengthen the body. The method combines principles of exercises from the Eastern cultures (control of motion by the mind, precision, body center as the main energy point, proper breathing and relaxation-Hatha-Yoga) and the Western cultures (endurance training, stabilization-classical ballet). According to Crews, the described training concept assumes reinforcing the muscles of the whole body, however, it is especially emphasizing conscious action exerted on deep muscular structures [10].

Most recent literature described Pilates as an effective activity able to increase body balance due to the stimulation on motor control, in particular for the abdominal region [11].

\section{Material and Methods}

\section{Ethical approva:}

The protocol of this study was approved by The Ethical Committee of the Faculty of the Physical Therapy, Cairo University From October 2020 - January 2021. (no: P.T. REC/012/ 003099). The program was explained for every patient and the work was confidential. Every patient in this study signed informed consent form to share in this study prior to participation.

\section{Study design:}

Two groups pre-test post-test design.

\section{Subjects:}

Thirty post-menopausal women complaining from belly abdomen were selected randomly from out-patient clinic of faculty of physical therapy to participate in this, their age ranged from 50-60 years, their BMI not exceed $35 \mathrm{Kg} / \mathrm{m}^{2}$, all of them had number of parities ranged from 2-4 times, their menstrual cycle had stopped at least one year ago. Subjects were subdivided randomly into two groups each with fifteen participants.

\section{Group A:}

This group consisted of 15 post-menopausal women complaining from belly abdomen who practiced selected exercise program that include (static abdominal, pelvic rocking and postural correction exercises) for $20 \mathrm{~min} / \mathrm{session}$ twice per week for 12 weeks.

\section{Group B:}

This group consisted of 15 post-menopausal women complaining from belly abdomen who practiced the same exercise program of group A plus Pilates exercises for another $60 \mathrm{~min} / \mathrm{session}$ for the same period of 12 weeks [12].

\section{Materials:}

\section{Informed consent form:}

Recording data sheet:

All data and information of each patient who participated in this study including name, age, address, weight and height, numbers of parity, date of last menstrual cycle were recorded in recording data sheet.

Standard weight and height scale: It was used to measure weight $\&$ height to calculate body mass index (BMI) for each patient in both groups (A\&B) before the beginning of the study.

Isokinetic dynamometer: It was used to measure strength of abdominal muscles in form of peak torque, total work and average power for each patient before and after study.

Procedures:

A- Evaluation procedures:

Body mass index (BMI) measurement:

Weight and height scale was used to measure weight and height for each woman in both groups (A\&B) before the treatment to calculate their BMI according to the following equation:

$$
\text { BMI }\left(\mathrm{kg} / \mathrm{m}^{2}\right)=\text { Weight }(\mathrm{Kg}) / \text { Height }\left(\mathrm{m}^{2}\right) \text {. }
$$

\section{Abdominal muscles strength:}

Isokinetic Dynamometer: (Biodex medical system,Shirley, New York, USA) was used to assess the abdominal muscles strength for all women in both study and control group before initiating the study and after 12 weeks of the treatment program. The Biodex system represents a high level of performance, validity, accuracy and safety [13]. A full demonstration about the device and how to carry out the assessment were given to every woman. It is recommended to perform three consecutive training trials before the actual testing procedure. The woman was asked to seat on the isokinetic seat with her back at $120^{\circ}$ with the thigh well supported on the back of the seat throughout the testing procedure via using adjustable straps. Both knees were kept at $90^{\circ}$ flexion, both feet should be supported on foot support. Then the computer 
was adapted at the parameters required for assessing the trunk flexion, with angular velocity set at $60 \%$ for both trunk flexion and extension. Then the woman was informed that once she received the starting signal, she moves her trunk smoothly towards her thighs as far as she could, then returned her trunk again to the starting position, she was asked to repeat this movement for a number of 5 successive repetitions. The assessor considered the best repetition of them for data analysis. Then the results were saved into the computer as follow: Peak torque, total work and average power [14].

\section{B- Treatment procedures:}

\section{I- Group A:}

This group consisted of 15 post-menopausal women complaining from belly abdomen who practiced selected exercise program that include (static abdominal, pelvic rocking and postural correction exercises) for $20 \mathrm{~min} / \mathrm{session}$ twice per week for 12 weeks.

\section{Static abdominal exercises:}

Static abdominal exercise a type of exercise aimed to increase strength of abdominal muscle, the woman in supine lying with her arms placed over the abdomen then she was asked to draw or pull the abdomen inwards so that there is an isometric contraction of abdominal muscles and repeat this for 5 to 7 times for $10 \mathrm{~min}$.

\section{Pelvic rocking exercises:}

This exercise strengthens the back, hip, and abdominal muscles. The woman was positioned on her hands and knees, with her hands placed directly under her shoulders and the knees under the hips. Then she was asked to breathe in deeply, tuck her head downward and round her back up, making a curve with her back in the shape of the letter C. Hold this position for a count of 6 , then breathe out slowly and bring her head back up. Relax, keeping the back straight-don't allow it to curve toward the floor. Hold this for a count of 6 , this exercise was done 8 times for $5 \mathrm{~min}$.

\section{Postural correction exercises:}

Post-menopausal woman was positioned on crock lying with their hips and knees at 60 . angles of flexion and their lumbar vertebra in the neutral position. A towel was placed under the occiput to support the weight of the head and the cervical spine, and both hands were comfortably positioned on either side of the body, then she was asked to contract abdominal and gluteal muscles while maintaining her breath in and out smoothly. Hold this for a count of 6 , this exercise was done 8 times for $5 \mathrm{~min}$.

\section{II- Group B:}

This group consisted of 15 post-menopausal women complaining from belly abdomen who practiced the same exercise program of group A plus Pilates exercises for another $60 \mathrm{~min} / \mathrm{session}$ for the same period of 12 weeks.

\section{Pilates exercises:}

Each woman was instructed briefly and clearly about the benefits of Pilates exercise to gain their confidence and cooperation of all through the period of this study.

Pilates exercise program included a starting 10 min warm-up with very low-intensity exercises, including breathing and joint mobility exercises carried out in upright position. The central part of the protocol had a duration of $40 \mathrm{~min}$ and included only floor exercises such as one leg circle, single leg kick, double leg kick, side kick, one leg stretches, single leg heel, single leg toes, side lying hip abduction, side lying hip adduction, roll up, rolling back, leg rises on all fours, pelvic curl, and the hundred. The last exercise, the hundred, is a classic Pilates mat exercise that expected to maintain a standard position with feet off from the floor, knees bent at a 90 angle, arms long and just above the abdominal floor, head and shoulders curled off from the floor. At the same time, subjects had to use abdominal muscles to support the head and move arms up and down at side energetically keeping time to the 4-count breath in and the 6count breath out. Two sets per 10 repetitions were executed for each exercise in order to standardize the volume of the intervention. Finally, subjects performed a 10-min cool down consisting of stretching exercises. All sessions were supervised by an exercise specialist, with a teaching certification in Pilates methodology.

\section{Statistical analysis:}

Unpaired $t$-test was conducted for comparison of subject characteristics between groups. The normality of data was checked using Shapiro-Wilk test. Levene's test was used to check the homogeneity between groups. Mixed MANOVA was performed to compare within and between groups effects on peak torque, total work and average power of abdominal muscles. Post-hoc tests using the Bonferroni correction were carried out for subsequent multiple comparison. The level of significance for all statistical tests was set at $p<0.05$. All statistical analysis was conducted through the statistical package for social studies (SPSS) version 22 for windows (IBM SPSS, Chicago, IL, USA). 


\section{Results}

\section{Subject characteristics:}

Table (1) showed the subject characteristics of the group A and B. There was no significant difference between both groups in the mean age, weight, height and BMI $(p>0.05)$.

Table (1): Comparison of subject characteristics between the study and control groups.

\begin{tabular}{llll}
\hline & \multicolumn{2}{c}{ Mean \pm SD } & \\
\cline { 2 - 3 } & Group A & Group B & $p$-value \\
\hline Age (years) & $54.6 \pm 2.32$ & $53.2 \pm 2.81$ & 0.14 \\
weight $(\mathrm{kg})$ & $66.6 \pm 2.82$ & $67.4 \pm 3.24$ & 0.47 \\
Height $(\mathrm{cm})$ & $156.46 \pm 2.87$ & $156.73 \pm 4.2$ & 0.84 \\
BMI $\left(\mathrm{kg} / \mathrm{m}^{2}\right)$ & $27.23 \pm 1.54$ & $27.5 \pm 2.17$ & 0.69 \\
\hline
\end{tabular}

SD: Standard deviation. $\quad p$-value: Probability value.

Effect of treatment on peak torque, total work and average power of abdominal muscles:

Mixed MANOVA revealed that there was a significant interaction of treatment and time $(\mathrm{F}=$ 9.97, $p=0.001)$. There was a significant main effect of time $(\mathrm{F}=115.74, p=0.001)$. There was a significant main effect of treatment $(\mathrm{F}=13.35, p=0.001)$.

\section{Within group comparison:}

There was a significant increase in peak torque, total work and average power of abdominal muscles in both groups A and B post treatment compared with that pretreatment $(p<0.001)$. (Table 2$)$.

\section{Between group comparison:}

There was no significant difference between groups in all parameters pretreatment $(p>0.05)$. Post treatment there was a significant increase in peak torque, total work and average power of abdominal muscles of group B compared with that of group A $(p>0.001)$.

Table (2): Mean peak torque, total work and average power of extensors and flexors pre and post treatment of the group A and B.

\begin{tabular}{|c|c|c|c|}
\hline & \multicolumn{2}{|c|}{ Mean \pm SD } & \multirow{2}{*}{$\begin{array}{c}p^{-} \\
\text {value }\end{array}$} \\
\hline & Group A & Group B & \\
\hline \multicolumn{4}{|l|}{ Peak torque (Nm): } \\
\hline Pre treatment & $21.68 \pm 2.66$ & $22.3 \pm 3.64$ & 0.6 \\
\hline Post treatment & $\begin{array}{l}26.15 \pm 2.47 \\
p=0.001\end{array}$ & $\begin{array}{l}28.86 \pm 3.82 \\
p=0.001\end{array}$ & 0.02 \\
\hline \multicolumn{4}{|l|}{ Total work $(J)$ : } \\
\hline Pre treatment & $15.26 \pm 1.28$ & $16.13 \pm 1.76$ & 0.13 \\
\hline Post treatment & $\begin{array}{l}17.8 \pm 2.67 \\
p=0.001\end{array}$ & $\begin{array}{l}21.8 \pm 3.7 \\
p=0.001\end{array}$ & 0.002 \\
\hline \multicolumn{4}{|c|}{ Average power (Watt): } \\
\hline Pre treatment & $13.66 \pm 1.8$ & $14.33 \pm 1.34$ & 0.26 \\
\hline Post treatment & $\begin{array}{l}16.46 \pm 2.2 \\
p=0.001\end{array}$ & $\begin{array}{l}20.93 \pm 2.6 \\
p=0.001\end{array}$ & 0.001 \\
\hline
\end{tabular}

\section{Discussion}

Menopause is the ultimate marker of the conclusion of a woman's reproductive period. Characteristic menopause happens between the age of 40 and 60 a long time in most women [15]

Female sex hormones have wide-ranging impacts on women's health and well-being over the life expectancy. Amid midlife, women involvement exceptional hormonal changes due to ovarian aging and the resulting menopausal move. The menopausal move stage incorporates height of the serum follicle-stimulating hormone (FSH) concentration and a decrease within the estradiol concentration, both of which exhibit wide interindividual variety $[2,16]$. Muscle and bone mass decrease with maturing, expanding the risk for sarcopenia and osteoporosis in afterward life [17,18]

Pilates may be a well-known frame of work out that joins breathing, movement, and control of body pose. It has been commonly utilized in physical preparing and restoration programs [19]. Pilates includes an arrangement of works out that combine center soundness, breathing, posture, muscle quality, and flexibility [20]. The work out escalated is adapted to patients' inability levels and aptitudes and can be connected in a person or group-based program [21]

This study aimed to see the impact of Pilates exercise on abdominal muscle strength in postmenopausal women.

Thirty post-menopausal women complaining from belly abdomen were selected randomly from out-patient clinic of faculty of physical therapy to participate in this study, their age ranged from 5060 years, their BMI not exceed $35 \mathrm{Kg} / \mathrm{m}^{2}$, all of them had number of parities ranged from 2-4 times, their menstrual cycle had stopped at least one year ago. Subjects were subdivided randomly into two groups each with fifteen participants, group A practiced selected exercise program that include (static abdominal, pelvic rocking and postural correction exercises) for $20 \mathrm{~min} / \mathrm{session}$ twice per week for 12 weeks and group B performed the same program as for group A plus Pilates exercises for another $60 \mathrm{~min}$. Outcome to be studied in this research was abdominal muscle strength (peak torque, total work and average power) using Isokinetic dynamometer.

The result showed that there was a significant increase in peak torque, total work and average power in abdominal muscles in group B who perform Pilates exercise rather than group A $(p>0.001)$. 
Pilates has similarities with spinal stabilization training, both aiming to normalise spinal motor control and emphasizing Transversus abdominis (TrA) and Obliquus internus abdominis (OI) recruitment [22].

Transversus abdominis and OI are activated during Pilates exercises when performed by experienced practitioners [23]. Pilates training is claimed to increase activation of $\operatorname{TrA}$ and OI during athletic or daily living activities, which is said to improve sporting performance and reduce back pain [24]

The result of this study comes in agreement with those of Bergamin and his colleagues who reported that Pilates exercise training could be an effective - method to improve abdominal strength (AST) [12]

Also, our results run on the same way with Gaskell and his colleagues who stated that Most participants considered that Pilates group exercises resulted in a combination of physical benefits, including increased core strength, improved posture and body awareness, improved flexibility, increased joint stability, and improved balance and function [25].

In the same line with our results the results of Maigorzata and his colleagues as they concluded that Pilates exercise program improved healthrelated quality of life and functionality more than trunk strengthening exercises at every stage of assessment [26].

Also, the results of the current study come in agreement with Shah who reported that Pilates strengthens the whole body, targeting each muscle group evenly with a mixture of dynamic and static strength training. No body part is neglected. We also work on all planes of movement - sitting, lying and standing. This means that the muscles are worked from many different directions, producing a uniform and very deep strength and tone, even without using heavy weights Pilates builds strength from the inside out, from the deep core muscles, so that they support the body effectively in movement, and outwards to the limbs, Pilates builds endurance within individual exercises and also within workouts. Focus on improving the concentration to build strength for both - endurance comes first from mental strength and therefore requires determination and persistence. Visualize the success and becoming stronger, and stay strong through challenging exercise [27]

\section{Conculsion:}

Pilates exercises has effect on abdominal muscle strength in post menopausal women.

\section{Source of funding:}

This study received no financial support.

\section{Conflict of interest:}

The authors have no conflict of interest.

\section{Acknowledgment:}

The authors would like to thank all individuals who contribute to the completion of this work, especially women who participate in this study.

\section{References}

1- GOLD E.B., BROMBERGER J., CRAWFORD S., et al.: Factors associated with age at natural menopause in a multiethnic sample of midlife women. Am. J. Epidemiol., 153: 865-874, 2001.

2- HARLOW S.D., GASS M., HALL J.E., LOBO R., MAKI P., REBAR R.W., et al.: Executive summary of the Stages of Reproductive Aging Workshop + 10: Addressing the unfinished agenda of staging reproductive aging. J. Clin. Endocrinol. Metab., 97: 1159-1168, 2012.

3- DENNERSTEIN L., DUDLEY E.C., HOPPER J.L., et al.: A prospective population-based study of menopausal symptoms. Obstet. Gynecol., 96: 351-8, 2000.

4- MESSIER V., RABASA-LHORET R., BARBATARTIGAS S., et al.: Menopause and sarcopenia: A potential role for sex hormones. Maturitas, 68: 331-336, 2011.

5- FERRUCCI L., BARONI M., RANCHELLI A., LAURETANI F., MAGGIO M., MECOCCI P. and RUGGIERO C.: Interaction between bone and muscle in older persons with mobility limitations. Current Pharmaceutical Design, 20 (19): 3178-3197, 2014

6- ABELLAN VAN KAN G.: Epidemiology and consequences of sarcopenia, J. Nutr. Health Aging, 13: 708-712, 2009.

7- MALTAIS M.L., DESROCHES J. and DIONNE I.J.: Changes in muscle mass and strength after menopause. J. Musculoskelet Neuronal Interact, 9 (4): 186-97, 2009.

8- MENTLE J., HASLAM J. and BARTON S.: Physiotherapy in obstetrics and gynecology, 2 nd edition 2004.

9- GUNNARSSON U., STARK B. and DAHLSTRAND U.: Correlation between abdominal rectus diastasis width and abdominal muscle strength. Dig. Surg., 32 (2): 112-116, 2015.

10- CREWS L.: Pilates: Philosophy and biomechanics. American Fitness, 2: 58-62, 2006.

11- GRANACHER U., GOLLHOFER A., HORTOBAGYI T., KRESSIG R.W. and MUEHLBAUER T.: The importance of trunk muscle strength for balance, functional performance, and fall prevention in seniors: A systematic review. Sports Med., 43: 627-641, 2013.

12- M. BERGAMIN, S. GOBBO, V. BULLO, T. ZANOTTO, B. VENDRAMIN, F. DUREGO L. CUGUSI, V. CAMOZZI, M. ZACCARIA, D. NEUNHAEUSERER and A. ERMOLAO: Effects of a Pilates exercise program on muscle strength, postural control and body composition: Results from a pilot study in a group of post-menopausal wome, 37-118, 2015. 
13-ZAWADZKI J., BOBER T. and SIEMIENSKI A.: Validity analysis of the Biodex System 3 dynamometer under static and isokinetic conditions. Acta. Bioeng. Biomech., 12 (4): 25-32, 2010.

14- EL-MEKAWY H., ELDEEB A., EL-LYTHY M. and ELBEGAW A.: Effect of Abdominal Exercises versus Abdominal Supporting Belt on Post-Partum Abdominal Efficiency and Rectus Separation. International Journal of Medical and Health Sciences, 7 (1): 75-79, 2013.

15- SCHOENAKER D.A., JACKSON C.A., ROWLANDS J.V. and MISHRA G.D.: Socioeconomic position, lifestyle factors and age at natural menopause: A systematic review and meta-analyses of studies acrosssix continents. Int. J. Epidemiol., 43: 1542-562, 2014.

16- TEPPER P.G., RANDOLPH J.F., McCONNELL D.S., CRAWFORD S.L., EL KHOUDARY S.R., JOFFE H., et al.: Trajectory clustering of estradiol and folliclestimulating hormone during the menopausal transition among women in the Study of Women's Health across the Nation (SWAN). J. Clin. Endocrinol. Metab., 97: 2872-2880, 2012.

17- SCHIESSL H., FROST H.M. and JEE W.S.: Estrogen andbone-muscle strength and mass relationships. Bone, 22: 1-6, 1998.

18- FROST H.M.: On the estrogen-bone relationship and postmenopausal bone loss: A new model. J. Bone Miner Res., 14: 1473-1477, 1999.

19- PILATES K.J.: How does it work and who needs it? Muscles Ligaments Tendons J., 1: 9 (2): 61, 2011.

20- WELLS C., KOLT G.S. and BIALOCERKOWSKI A.: Defining pilates exercise: A systematic review complement Ther Med., 20: 253-262, 2012.
21- PATTI A., BIANCO A., PAOLI A., et al.: Effects of pilates exercises programs in people with chronic low back pain: A systematic review.Medecine, 94: 1, 2015.

22- RICHARDSON C.A.P., HODGES P.W. and HIDES J.A.P.: Therapeutic exercise for Lumbopelvic stabilization, A motor control Approach for the treatment and Prevention of low back pain. 2 nd ed. Edinburgh: Churchill Livingstone, 85: 470, 2004.

23- ENDLEMAN I. and CRITCHLEY D.J. :Transversus abdominis and obliquus internus activity during pilates exercises: Measurement with ultrasound scanning. Archives of Physical Medicine and Rehabilitation, 89: 22052212,2008

24- MUSCOLINO J.E. and CIPRIANI S.: Pilates and the "powerhouse" eI. Journal of Bodywork and Movement Therapies, 8: 15-24, 2004.

25- GASKELL L., WILLIAMS A. and PREECE S.: Perceived benefits, rationale and preferences of exercises utilized within Pilates group exercise programmes for people with chronic musculoskeletal conditions: A questionnaire Pilates-trained physiotherapists, 17: 206-214, 2019.

26- MALGORZATA ZGORZALEWICZ-STACHOWIAK, KRYSTYNA ZEN'CZAK-PRAGA ELIKS M., et al.: Application of Pilates-based exercises in the treatment of chronic non-specific low back pain: State of the artMal'gorzata Eliks, Postgrad Med. J., 0: 1-5, 2019.

27- SHAH S.: SPB Physiotherapy College, Ugat Bhesan road, Surat, Gujarat, India-International Journal of Physiotherapy and Research, Int. J. Physiother Res., 1 (4): 196-203, 2013.

\section{تأثير "تمرينات بيلاتس" على قوة عضلات البطن للدى السيدات بعد انقطات على فوة الطمث}

\footnotetext{
يتناول هذا البحث تأثير "تمرينات بيلاتس" على قوة عضلات البطن لدى السيدات بعد انقطاع الطمث.

انقطاع الطمث هى الفترة التى تحدث فى متوسط عمر اه ويحدث خلالها انخفاض فى نسبة هرمون الاستروجين الذى يؤدى إلى زيادة

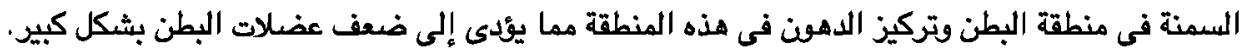
"تمرينات بيلاتس" هي مجموعة من التمرينات التى تحسن الحالة الجسدية والذهنية وتزيد من قوة العضلات.

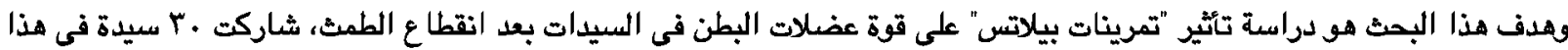

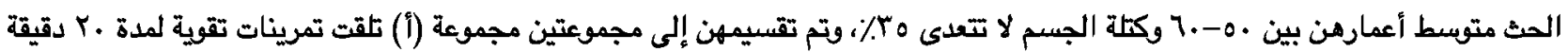

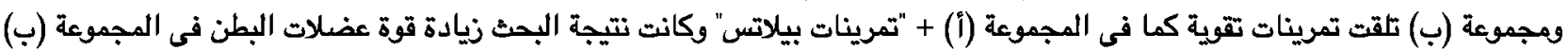

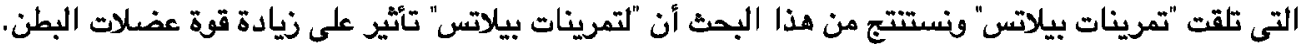

